This is the Accepted Manuscript version (post-print). Please cite the article as follows:

Esgarrancho, S. and Cândido, C.J.F. (2020) Firm preparation for ISO 9001 Certification - The case of the hotel industry in Portugal. Total Quality Management \& Business Excellence, 31(1), 23-42.

You can download a free copy of the paper, in the editor's format, clicking on the following link: https://www.tandfonline.com/eprint/S8XPH6PIGRMQNSXEXY3K/full?target=10.1080/14783363.2017.1404428. Please click only once as the number of free downloads is limited. If there are no more downloads available on this link, try the alternative link: http://www.tandfonline.com/eprint/pUdCqE3m4dSsRrN9hA25/full.

HTML: http://www.tandfonline.com/doi/full/10.1080/14783363.2017.1404428

DOI : http://dx.doi.org/10.1080/14783363.2017.1404428

The Version of Record of this manuscript has been published and is available in Total Quality Management \& Business Excellence, Vol. 31, Issue 1, 2020, http://www.tandfonline.com/doi/full/10.1080/14783363.2017.1404428.

\title{
Firm preparation for ISO 9001 Certification - The case of the hotel industry in Portugal
}

\author{
Sandra Esgarrancho ${ }^{\mathrm{a}}$ and Carlos J.F. Cândido ${ }^{\mathrm{a}, \mathrm{b}}$ \\ ${ }^{a}$ Faculty of Economics, University of Algarve, Faro, Portugal; ${ }^{b}$ CEFAGE, Évora, Portugal.
}

\begin{abstract}
The purpose of this study is to assess whether companies conduct preparations, such as managing culture, before starting to implement an ISO 9001 Quality Management System (QMS). Based on a literature review, the paper develops a model of firm preparation for ISO 9001 certification and several research hypotheses.

The survey research method adopted consists of data collection through questionnaires - sent to hotels of four and five stars, in Portugal, in two different moments (2012 and 2014) - and of a longitudinal data analysis based on nonparametric statistical
\end{abstract} tests.

Results show that the majority of companies conduct preparations before starting to implement an ISO 9001 QMS. However, most companies do not assess their initial situation, nor do they plan for the preparations. One of the significant implications from this research is that a more coherent and integrated approach in ISO 9001 preparation is required. Other implications for practice and for research are also noted.

This is the first study, as far as the authors are aware of, that addresses the topic of planning for the preparations that a company can make before starting to implement an ISO 9001 QMS.

Keywords: culture, implementation, incipient, ISO 9000, plan, preparation, quality management system. 


\section{Introduction}

Certification requires time and effort so that the standard's requirements are appropriately implemented. Some companies may start preparing for the certificate after they decide to initiate the certification process, but others may start preparing earlier. In this study, the authors intend to analyse whether companies prepare for the certification (and how) before they formally start the certification process. This preparation stage is defined here as a certification step, that may benefit from the support of consultants, but is prior to contact with any auditing entity and, in some cases, prior to the decision to obtain the ISO 9001 certificate. As far as we know, there are no studies on this period of preparation. There are, however, some studies that analyse how the previous existence of a Quality Management System (QMS) might facilitate the implementation of a ISO 9001 certificated system (e.g.: Withers et al., 1997), and studies addressing the importance of the analysis of the company situation before the certification process (Briscoe et al., 2005), but there are no studies on the existence (and characteristics) of a previous preparation process for certification in the manner in which it is viewed in this research.

A model of this certification preparation process was developed based on the literature review, and four research hypotheses were concurrently formulated. In an attempt to test these hypotheses, a survey method was adopted. Two questionnaires were sent by electronic means, in 2012 and 2014, to collect the necessary data. The research methodology involved a comparison of the survey results in 2012 and 2014, which permitted an evaluation of the current status and of the recent developments in the preparation process for certification. Both surveys were carried out in the four and five stars hotels, in Portugal, where the tourism sector is one of the most significant economic activities.

The article structure is the following. Section 2 includes the literature review, the research model, and the research hypotheses. Section 3 explains the research 
methodology. Section 4 shows the results of the statistical tests performed for both years under study and makes a comparison of these results. Finally, sections 5 and 6 present the discussion, contributions, implications, limitations, and recommendations for future research

\section{Literature review}

\subsection{Quality in tourism services}

Several factors have contributed to an increase in quality awareness in the tourism sector. These factors include the high growth rate of the tourism industry (Chaiprasit et al., 2011), the fierce competition in the sector (Stăncioiu et al., 2011), and the increase in customer expectations and demands. Because of these factors, tourism destinations and tourism organizations are also "increasingly determined to convey a unique and competitive identity within the consumer's mind". Quality of the services - which might be defined as a bundle of attributes timely delivered to customer satisfaction (Bisgaard, 2008) - helps creating the competitive identity and customer loyalty that tourism destinations and tourism organizations desire. Consequently, quality has become a critical success factor and has received an increased attention, both from managers and researchers.

Although the interest in quality has grown, with tourism organizations trying to adapt their services to customers' expectations and needs, quality certification through ISO 9001 is still a relatively recent phenomenon in the tourism industry (Mahony, 2007). The total number of ISO 9001 certified tourism organizations in the world is only 4340 (ISO, 2016), a very small number when compared to the millions of firms in the tourism sector (1.6 million only in Europe, according to Eurostat, 2012:310).

These numbers make this sector a very large potential market for certification, and an adequate context to analyse firm preparation for ISO 9001, even if the stagnation/ decline in the number of certified companies (ISO, 2016) cannot be reverted. 


\subsection{ISO 9001}

A ISO 9001 QMS can contribute to identify customer's needs, establish quality standards, ensure that customers' requirements are met and enable the objectives set out in the quality policy to be achieved (Evans and Lindsay, 2014). However, ISO 9001 adoption implies several modifications that have an impact, not only on the role of top management, but also on the functioning of key internal processes in the organization (ISO, 2015). Thus, it is important that employees have prior knowledge of the changes that will be implemented and that they are receptive to these changes.

If the certification process is not properly managed and employees are not receptive, implementation might not be successful, or may cause undesired effects such as unforeseen costs, excessive bureaucracy, insufficient attention to resource development, and discouragement of critical and creative thinking in the company (Singels et al., 2001; Anttila and Jussila, 2017).

The newer version of the ISO 9001 standard, issued in 2015, is more pragmatic, less prescriptive, and focuses more on results and less on documentation than previous versions (Croft et al., 2016). But remains founded on basically the same quality principles (Anttila and Jussila, 2017) and adds new requirements (e.g., risk based approach and knowledge management), which suggest that proper certification (and recertification) under ISO 9001:2015 continues to pose several challenges (Rybski et al., 2017) and may still require a significant cultural change in the organization.

\subsection{Organizational culture}

Culture reflects organizational values, philosophy and business identity. It involves organizational aspects such as assumptions, symbols, rituals, dress codes, and others (Schein, 1983). These aspects are very important because they can influence people's behaviours (Schein, 1983) and their responses to organizational change efforts. In fact, 
even in a context dependency view, culture is a key variable for success (or failure) of any organizational transformation (Balogun and Hailey, 2015). Culture influences implementation of QMSs (Gambi et al., 2015) and can be seen as one of the most important aspects of quality certification processes (Valmohammadi and Roshanzamir, 2015).

Terziovski et al. (1997) and Gambi et al. (2015) suggest that ISO 9001 certification contributes to an improvement of the organization's performance only if the company has or creates a favourable climate for change. It is often difficult to implement successfully certified QMSs due to the sharp change required in the company culture (Valmohammadi and Roshanzamir, 2015). Consequently, firms need to be actively aware of their cultural characteristics (Gambi et al., 2015), and the top management team must play a key role in implementing a culture of continuous improvement and innovation (Kanji and Sá, 2002).

Unfortunately, the ISO 9001 standard, on itself, does not promote the cultural transformation that is needed to be successful (Yung, 1997, Dalmau et al., 2016). A company that has previously included quality in its organizational culture, through the implementation of a Total QMS (or other initiatives related to quality), may however have a lesser need for cultural change and, therefore, lesser difficulties to include in its routines the changes that are necessary for certification (Withers et al., 1997; Terziovski and Power, 2007; Martínez-Costa et al., 2009).

\subsection{Preparation for ISO 9001 certification}

This paper researches whether, before the certification process takes place, companies prepare for a successful certification. Preparation can help to increase prior knowledge about quality, reduce resistance to change, increase employees receptivity to change, and facilitate future implementation of the ISO 9001 QMS (Briscoe et al., 2005; Cândido, 
2005, 2010). However, prior knowledge and receptivity to organizational change are not achieved easily nor quickly (Kotter, 2007). They might be achieved through a communication effort by the organization's leaders, an investment in personnel training and through other preparatory activities related to ISO 9001 certification (Figure 1).

Figure 1. Preparation for ISO 9001 certification: pre-certification initiatives

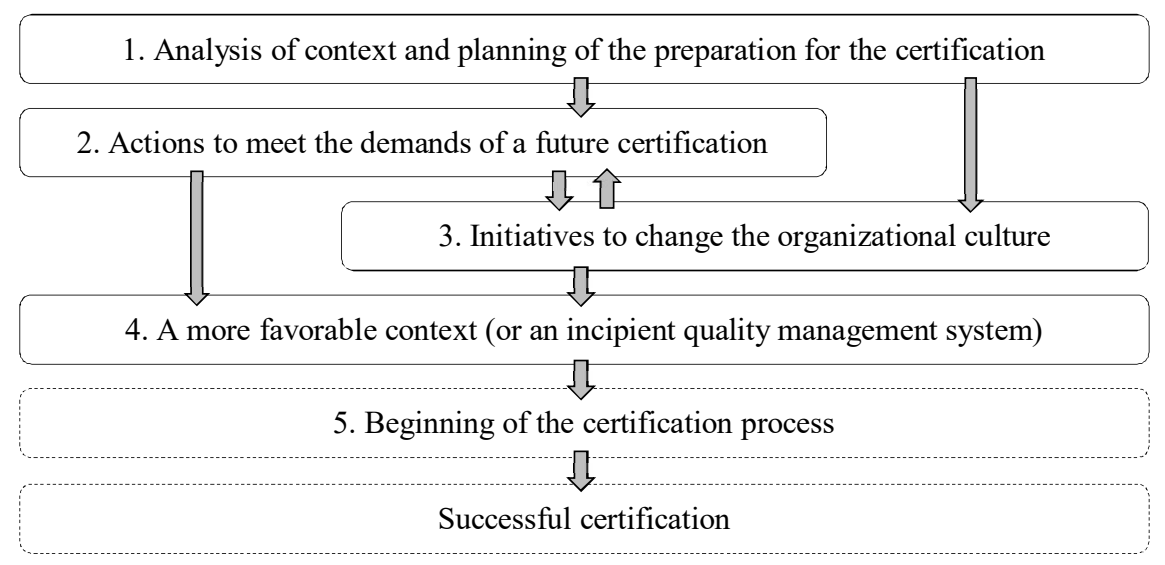

The model in Figure 1 suggests that the company should carry out a series of steps before beginning certification. These steps aim for the installation of an incipient QMS, i.e., an organizational context where there are some of the basic components of the future QMS and more receptivity to the changes required by certification. Once the certification process begins, the company will then be in a better position to implement the ISO 9001 standards and to do it more easily.

This model suggests that the organization first conducts an analysis of the precertification situation and plans a set of initiatives to be implemented (Step 1). During this step, managers should consider their company's ability to implement an ISO 9001 QMS (Briscoe et al., 2005) and evaluate the company's organizational culture (Briscoe et al., 2005; Gambi et al., 2015; Anttila and Jussila, 2017). The step may include activities such as gap analysis, barriers anticipation, planning, and effective communication with 
people. Thus, the analysis and planning are the starting point for the development of a set of preparatory initiatives that will help to meet the requirements of a future certification.

Steps 2 and 3 enable the organization to adopt some of the basic components of a QMS, which may be part of the ISO requirements (ISO, 2008, 2015). These components can include both hard and soft QMS elements, namely, customer needs identification, quality measurement, customer satisfaction assessment (Step 2), communication, debate, brainstorming, education, involvement, and common language development (Step 3). For a more extensive (but not exhaustive) list of quality activities/ initiatives and methods that can be implemented in steps 2 and 3, see left column of Table 6 and compare with Table 2 of Rahman (2004) and ISO (2008, 2015).

Steps 2 and 3 imply that the implementation of hard QMS elements alone is not effective, and needs a receptive quality culture (soft QMS elements) (Rahman and Bullock, 2005; Srinivasan and Kurey, 2014; Gambi et al., 2015). Receptivity to change is developed simultaneously with the development of quality features in the organization. (Note the reciprocity between steps 2 and 3 in Figure 1.)

According to Naor et al. (2008), performing certain actions or small team projects - such as brainstorming sessions - can contribute to a culture and a context that is more receptive to change (Step 4). Briscoe et al. (2005) also note that as "a company establishes a quality culture ... barriers [to implementation] will be diminished and ... readiness for change will be enhanced" (Step 4).

Figure 1 concludes with the end of a successful certification process, which constitutes the implementation of an effective ISO 9001 QMS that improves performance and is not limited to a certificate that can be shown to customers.

\subsection{Hypotheses development}

The first research hypothesis deals with the role of top management in defining an action 
plan for the installation of an internal organizational context that is more receptive to ISO 9001 standard. According to Terziovski et al. (1997), Feng et al. (2008) and Cândido et al. (2016), ISO 9001 can contribute to organizational performance only if implementation of the standards is well planned. Top management is responsible for assessing the company situation, planning for quality, leading, organizing, and controlling implementation (Juran and Gryna, 1993). The literature further suggests that top management should take the initiative to analyse and understand the ISO 9001 standards prior to their introduction. Managers should also "carefully assess the threats to internalization before proceeding with ISO certification" (Briscoe et al., 2005), because management is responsible for defining the quality strategy, for anticipating possible obstacles, and for the execution of actions that allow a successful implementation (Juran and Gryna, 1993; Cândido and Santos, 2011, 2015). In general, an organization should consider the critical success factors for ISO 9001 certification since the early phases of their planning and it should define its quality plan to ensure that its efforts reflect the long-term goals of the organization (Kaziliūnas, 2010:70). In accordance with these principles, it can be hypothesized that top management plays a crucial role in the development of an action plan that contains initiatives to facilitate the certification process and the motivation of all personnel towards quality.

H1: Before starting the ISO 9001 registration process, companies deliberately prepare action plans (consisting of initiatives aimed at implementing an incipient QMS).

Following the adoption of the plan, the company implements specific actions, initiatives or tools that contribute to creating an internal organizational context that is more receptive to future certification. Training is one of these types of initiatives. As is well known, the ISO 9001 standard requires that the organization's employees have the 
necessary training and preparation to be able to perform the new tasks that are required by certification (e.g., ISO 9001:2015). Previous experience with initiatives, actions or incipient QMSs can also contribute positively (Vloeberghs and Bellens, 1996; Lo and Chang, 2007), alongside with training, to the preparation that the employees need and, concurrently, to increase the receptivity to ISO 9001 standards. In the same way that some companies adopt TQM before starting the certification process, others adopt ISO 9001 before attempting to become TQM companies. In each case, the previous experience with a quality system seems to facilitate the subsequent implementation of another/different quality system (Vloeberghs and Bellens, 1996; Gotzamani and Tsiotras, 2001; Lo and Chang, 2007). This idea, however, is not consensual, as Rahman (2001) and MartínezLorente and Martínez-Costa (2004) found no benefit in the performance of companies that have implemented two QMSs.

In accordance with this literature review, research hypothesis 2 proposes that companies that implement quality initiatives, quality related activities, quality management tools or even QMSs, before beginning the certification process, should find the subsequent implementation of ISO 9001 more facilitated. This hypothesis attempts to generalize the positive effects of early implementation of TQM, found in some studies, suggesting that the implementation of previous initiatives, actions and methods (even if loose or isolated and independent from the existence of a quality system), facilitate the subsequent certification of the company.

$\mathrm{H} 2$ : Before starting the ISO 9001 registration process, companies deliberately implement initiatives, actions, or quality management tools (aimed at creating an internal organizational context that is more receptive to certification). 
Hypothesis 3 is concerned with how organizational culture can affect the implementation of ISO 9001. Culture affects the organization's ability to achieve ISO 9001 certification, and the desired quality and market benefits (Briscoe et al., 2005). Culture incorporates assumptions, values, norms, symbols, and other aspects of organizational identity; all of them highly respected and adhered to by organizational members (Schein, 1983). The implementation of changes, which are not in accordance with such identity aspects, is usually unwelcome, making culture a major obstacle to the implementation of major organizational changes (Balogun and Hailey, 2015). In the case of ISO 9001, "one of the most prominent challenges to ISO implementation comes from employees who resist change" (Briscoe et al., 2005). Consequently, in order to contribute to organization performance, implementation of ISO 9001 standards must be preceded by creation of a climate of change in the organization (Terziovski et al., 1997; Feng et al., 2008; Cândido et al., 2016).

The management of the change process is a vital element in influencing staff (Hughes et al., 2000). Managers "need to be actively aware of the cultural characteristics of their organization before adopting quality techniques, in order to benefit most from the use of these techniques" (Gambi et al., 2015). Managers can also contribute to facilitating implementation through other initiatives, including a members' behavioral diagnostic, creating a shared understanding of the reasons for change, instaling adequate information systems, training, and other management initiatives (see, for instance, Kotter, 2007; Balogun and Hailey, 2015). These can contribute to starting a change in the culture and to make it more receptive for the desired ISO certification. In accordance, this study's hypothesis 3 , states that organizations start to change their culture before attempting the ISO 9001 registration because the "common denominator that led to failure in all ... quality efforts was that [companies] did not change the culture or the environment in 
which all these tools and processes were being used" (Detert et al., 2000; See also Gambi et al., 2015; Valmohammadi and Roshanzamir, 2015).

H3: Before starting the ISO 9001 registration process, companies deliberately carry out initiatives to begin to change the organizational culture (with the aim to create an internal organizational context that is more receptive to certification).

Because of the importance of quality in the tourism industry, many firms implement tools and principles associated with quality management, even if they do not have, nor wish to have, a QMS. The introduction of practices associated with quality, as well as the decision to obtain ISO 9001 certification, is usually voluntary, not mandatory. Companies can benefit from the implementation of quality principles, without a complete quality system, and can benefit from ISO 9001 standards, even if they do not receive formal ISO 9001 registration (Karapetrovic et al., 2010). Moreover, according to Briscoe et al. (2005), "companies that value and invest in quality are more adept at making quality a way of life". Similarly, companies that have implemented TQM prior to ISO $9001 \mathrm{can}$ achieve registration more easily. Consequently, companies that wish to be ISO 9001 registered should benefit from having previously implemented quality management initiatives, quality processes and/or other related quality systems (Vloeberghs and Bellens, 1996; Lo and Chang, 2007). Thus, the last research hypothesis focuses on the actions, initiatives, projects, or systems implemented by organizations, before they decide to start the certification process.

H4: Before starting the ISO 9001 registration process, companies deliberately take initiatives to adopt and implement an incipient QMS. 


\section{Methodology}

\subsection{Population and sample}

The target population of this study is composed of the four and five stars hotels in Portugal. These hotels were surveyed in two different years. The first one was 2012 and the second one was 2014. In 2012, the population was composed of 323 hotels, and the sample size was 24 , which corresponds to a response rate of valid answers of 7.4 percent. In 2014 , the population considered was slightly ampler than that of 2012 , because it included the four and five stars hotels located in the Portuguese archipelagos of the Azores and Madeira. In 2014, the population was, thus, 451 hotels. The final sample was composed of 29 valid responses, corresponding to a response rate of 6.4 percent.

\subsection{Data collection instrument}

The data collection instrument used in this study was an online survey. For the preparation of the questionnaire, the researchers conducted a literature review on ISO 9001 and a literature review on survey research methodology. Aspects that deserved particular attention were the sequence and structure of the issues addressed in the questionnaire, the wording of the questions, the number of questions, and the ease of understanding of the queries. The questions were separated into two groups, a group of questions about the issues being investigated, and another group of queries focusing on the characterization of the respondent and his/her hotel unit. A pre-test conducted with ten randomly chosen individuals suggested improvements to the wording of questions. The improved version of the questionnaire was again pretested until all interpretation doubts dissipated. After approving the last version of the questionnaire, the researchers sent the link to each of the two online questionnaires by e-mail, at several occasions, in order to increase the valid response rate. Response was anonymous, but each respondent was able to answer only once to each of the two questionnaires. 


\subsection{Hypotheses tests}

In order to test the research hypotheses, the best choice was to use non-parametric tests, because the data collected, in general asymmetrical, is inappropriate for parametric statistical tests. The particular test chosen was the Binomial test. This test is applied to an independent sample when the variable being tested is qualitative and dichotomous. The binomial test can examine whether the population proportion of one of the dichotomous features is equal to, smaller or larger than a certain fixed proportion $(\pi)$. Proportions considered for the tests in this paper were 10, 25, 33, 50, and 67 percent. The tests compare the observed frequencies with the expected frequencies, taken from a binomial distribution.

The statistical tests were first performed with the 2012 data, and then with the 2014 data. This procedure allows, first, an analysis of the results in each of those years and, second, a comparison between results and analysis of the evolution over the period considered.

Although non-parametric binomial tests are less demanding than parametric tests, still, some application conditions must be met. Non-response bias tests and randomness tests are conducted in order to assess whether the conditions for carrying out the binomial tests are present. Non-response bias tests assess the stability of the probability of an outcome over time. Randomness tests assess the independence of the successive observations being made.

\subsection{Non-response bias tests}

The main purpose of the non-response bias test is to check whether the respondents are significantly different from those individuals who did not respond. For this purpose, the Mann-Whitney test was applied to each of the two surveys conducted in 2012 and 2014. In each survey, the sample was separated into two groups, with approximately the same 
size: the group of responses that were received earlier and the group of responses that were received later. Then, various tests were carried out to compare the medians of the two groups of respondents for each of the research variables (or questionnaire queries). In most of the tests ( $>85$ percent), the significance levels were higher than 0.05 , and the hypotheses of equality of the medians of the two groups of observations were not rejected. Since no significant differences for most of the variables were detected, it was concluded that there is empirical evidence in favour of the absence of non-response bias.

\subsection{Randomness tests}

In this case, the researchers chose the Wald-Wolfowitz test to conduct the randomness tests for both samples. The variables previously used for the non-response bias test were again used for the randomness tests. The significance levels observed were all higher than 0.05 for all variables of both samples. This means that none of the randomness hypotheses should be rejected, and that there is empirical evidence in favour of data randomness in the two samples.

\section{Results}

\subsection{Sample characterization}

Table 1 shows the population structure, in terms of hotel category, and the structures of the two samples from 2012 and 2014.

Table 1. Population and samples' structures in terms of hotel category

\begin{tabular}{|c|c|c|c|c|c|c|c|c|c|c|}
\hline \multirow{3}{*}{ Category } & \multicolumn{4}{|c|}{ Population ${ }^{\text {(a) }}$} & \multicolumn{6}{|c|}{ Samples ${ }^{(b)}$} \\
\hline & \multicolumn{2}{|c|}{ No. of hotels } & \multicolumn{2}{|c|}{ Percentage } & \multicolumn{2}{|c|}{ No. of hotels } & \multicolumn{2}{|c|}{ Percentage } & \multicolumn{2}{|c|}{$\begin{array}{l}\text { Percentage of } \\
\text { the population }\end{array}$} \\
\hline & 2012 & 2014 & 2012 & 2014 & 2012 & 2014 & 2012 & 2014 & 2012 & 2014 \\
\hline Five stars hotel & 62 & 98 & 19.2 & 20.7 & 5 & 12 & 20.8 & 40.4 & 8.1 & 12.2 \\
\hline Four stars hotel & 261 & 353 & 80.8 & 78.3 & 19 & 17 & 79.2 & 58.6 & 7.3 & 4.8 \\
\hline Total & 323 & 451 & 100.0 & 100.0 & 24 & 29 & 100.0 & 100.0 & 7.4 & 6.4 \\
\hline
\end{tabular}

Source: (a) INE (2013, 2015), (b) survey data. 
The population consists mostly of four star hotels, but the proportion of these hotels has decreased from 2012 to 2014 . The samples also show a majority of four star hotels, and a reduction in percentage from 2012 to 2014. It can be seen that the structure of the 2012 sample did not differ much from the population's structure. However, the structure of the 2014 sample differed approximately 20 percent from that of the population. This difference did not seem to affect the representativeness of the sample, as was suggested by the randomness tests performed.

Regarding the hotel chain type of the respondents (Table 2), in the 2012 sample there was a majority of independent hotels (which did not belong to any chain) and in the 2014 sample there was a majority of hotels that belong to a national chain. There were very few international chain hotels in both samples. Unfortunately, there was no available information for the whole population that could be used for a comparison with the samples' structures.

Table 2. Hotel chains

\begin{tabular}{|l|c|c|c|c|}
\hline \multirow{2}{*}{ Chain type } & \multicolumn{2}{c|}{ No. of hotels } & \multicolumn{2}{c|}{ Percentage } \\
\cline { 2 - 5 } & 2012 & 2014 & 2012 & 2014 \\
\hline Hotel belongs to a national chain & 9 & 13 & 37.5 & 44.8 \\
\hline Hotel belongs to an international chain & 2 & 5 & 8.3 & 17.3 \\
\hline Independent hotel, does not belong to a chain & 13 & 11 & 54.2 & 37.9 \\
\hline Total & 24 & 29 & 100.0 & 100.0 \\
\hline
\end{tabular}

Source: Survey data

Table 3 shows the distribution of respondents in terms of the position they hold in the company. There was a variety of respondents' positions and the two samples differed in their composition. However, if separated in two groups, between management positions and others, the two samples remained very similar. In the 2012 sample there were 11 managers (45.8\%) and 13 respondents with other types of position (54.2\%). In the 2014 sample there were 16 managers (55.2\%) and 13 respondents with other positions $(44.8 \%)$. 
Table 3. Respondents' positions in the company

\begin{tabular}{|l|c|c|c|c|}
\hline \multirow{2}{*}{\multicolumn{1}{|c|}{ Position }} & \multicolumn{3}{c|}{ No. of respondents } & \multicolumn{2}{c|}{ Percentage } \\
\cline { 2 - 5 } & 2012 & 2014 & 2012 & 2014 \\
\hline General Manager & 5 & 13 & 20.8 & 44.8 \\
\hline Hotel Manager & 4 & - & 16.7 & - \\
\hline Departments Directors & 2 & - & 8.3 & - \\
\hline Quality Manager & - & 3 & - & 10.4 \\
\hline Assistance Manager & - & 2 & - & 6.9 \\
\hline Quality Technicians & - & 3 & - & 10.3 \\
\hline Other Superior Technicians & 13 & - & 54.2 & - \\
\hline Other & - & 8 & - & 27.6 \\
\hline Total & 24 & 29 & 100.0 & 100.0 \\
\hline
\end{tabular}

Source: Survey data.

Regarding the respondents' number of years of experience in the company (Table 4), the percentage distribution of both samples was very similar. The number of respondents with six or more years of experience in the company was 50.0 percent in 2012 and 59.6 percent in 2014.

Table 4. Years of experience in the company

\begin{tabular}{|c|c|c|c|c|}
\multirow{2}{*}{ Years of experience } & \multicolumn{2}{|c|}{ No. of respondents } & \multicolumn{2}{|c|}{ Percentage } \\
\cline { 2 - 5 } & 2012 & 2014 & 2012 & 2014 \\
\hline 0 to 5 years & 12 & 12 & 50.0 & 40.4 \\
\hline 6 to 10 years & 8 & 9 & 33.3 & 31.0 \\
\hline 11 to 20 years & 1 & 4 & 4.2 & 13.8 \\
\hline 21 to 25 years & 2 & 3 & 8.3 & 10.3 \\
\hline 26 or more years & 1 & 1 & 4.2 & 3.5 \\
\hline Total & 24 & 29 & 100.0 & 100.0 \\
\hline
\end{tabular}

\subsection{Hypotheses tests}

\subsubsection{Planning}

This section tests the hypothesis that before starting the ISO 9001 registration process, companies deliberately prepare action plans consisting of initiatives aimed at implementing an incipient QMS. The formal statistical hypotheses to test are the following:

$\mathrm{H}_{0}: \pi \leq 0.33$, the proportion of hotels, $\pi$, in the population, that deliberately prepare actions plans (with initiatives aimed at implementing an incipient QMS) is less than or equal to 33 percent. 


$$
\mathrm{H}_{\mathrm{A}}: \pi>0.33 \text {. }
$$

The significance levels obtained with the binomial tests performed are less than $\alpha=0.05$, which leads to the rejection of $\mathrm{H}_{0}$, both for 2012 and 2014 (see Table 5).

Table 5. Binomial tests results for hypothesis 1

\begin{tabular}{|l|c|c|c|c|c|c|c|c|}
\hline \multirow{2}{*}{ H1 (plan) } & \multicolumn{4}{|c|}{2012} & \multicolumn{4}{c|}{2014} \\
\cline { 2 - 8 } & $\begin{array}{c}\text { No. of } \\
\text { hotels }\end{array}$ & $\begin{array}{c}\text { Proportion } \\
\text { observed }\end{array}$ & $\begin{array}{c}\text { Significance } \\
\text { level for Ho: } \\
\pi \leq 0.33\end{array}$ & $\begin{array}{c}\text { Significanc } \\
\text { e level for } \\
\mathrm{H}_{0}: \pi \leq 0.50\end{array}$ & $\begin{array}{c}\text { No. of } \\
\text { hotels }\end{array}$ & $\begin{array}{c}\text { Proportion } \\
\text { observed }\end{array}$ & $\begin{array}{c}\text { Significanc } \\
\text { e level for } \\
\mathrm{H}_{0}: \pi \leq 0.33\end{array}$ & $\begin{array}{c}\text { Significance } \\
\text { level for Ho: } \\
\pi \leq 0.50\end{array}$ \\
\hline Plan & 11 & 0.550 & $0.035^{* *}$ & 0.412 & 15 & 0.577 & $0.008^{* * *}$ & 0.279 \\
\hline No plan & 9 & 0.450 & & & 11 & 0.423 & & \\
\hline Total & 20 & 1.000 & & & 26 & 1.000 & & \\
\hline
\end{tabular}

Notes: *** Significant at the one percent level. ** Significant at the five percent level. The symbol $\pi$ represents the true proportion of hotels in the population holding the caracteristic being tested.

Repeating the analysis with a proportion $\pi$ of 50 percent (Table 5) the results indicate that, in both years, $\mathrm{H}_{0}$ should not be rejected. This means that the proportion of hotels, in the population, that deliberately prepare actions plans with initiatives aimed at implementing an incipient QMS, is higher than 33 percent and lower than, or equal to, 50 percent.

Results also show a very slight improvement over time, because the sample proportion of companies with a plan increased from $11 / 20=0.55$ to $15 / 26=0.58$ (Table 5). However, this increase is not significant enough to warrant the conclusion that the same trend has also occurred in the population of Portuguese four and five stars hotels.

\subsubsection{Quality initiatives prior to the beginning of the certification process}

This section tests the hypothesis that, before starting the ISO 9001 registration process, companies deliberately implement initiatives, actions or quality management tools aimed at creating an internal organizational context that is more receptive to certification. An extensive list of initiatives, actions, and methods is listed in Table 6. This table is similar to the previous one as it presents the results of binomial statistical tests performed for each of the initiatives/ actions/ methods in the years 2012 and 2014. 
Adopting a proportion $\pi$ of 67 percent, and assuming a significance level of $\alpha=0.05$, the statistical tests lead to the rejection of $\mathrm{H}_{0}$ for all variables in 2012 and for the majority of variables in 2014 (see Table 6). This means that the proportion of hotels, $\pi$, in the population, that implement most of these quality initiatives, actions, or methods, before the certification process, is higher than 67 percent. For some quality initiatives, in 2014, the proportion is smaller than 67 percent, but not lower than 50 percent, except for internal audits (p-value 0.442) and assessment of existing procedures ( $p$-value 0.169 ), which are nevertheless higher than 33 percent (p-values 0.005 and 0.001 , respectively).

Table 6. Binomial tests results for hypothesis $2\left(\mathrm{H}_{0}: \pi_{\mathrm{i}} \leq 0.67 ; \mathrm{i}=1 \ldots 15\right)$

\begin{tabular}{|c|c|c|c|c|c|c|}
\hline \multirow[b]{2}{*}{ H2 (actions/initiatives/methods/tools) } & \multicolumn{3}{|c|}{2012} & \multicolumn{3}{|c|}{2014} \\
\hline & Total & $\begin{array}{c}\text { Proportion } \\
\text { observed }\end{array}$ & $\begin{array}{c}\text { Significance } \\
\text { level }\end{array}$ & Total & $\begin{array}{c}\text { Proportion } \\
\text { observed }\end{array}$ & $\begin{array}{c}\text { Significance } \\
\text { level }\end{array}$ \\
\hline Education / employee training & 23 & 1.00 & $0.000 * * *$ & 27 & 0.96 & $0.000 * * *$ \\
\hline Employee involvement & 23 & 1.00 & $0.000 * * *$ & 26 & 0.96 & $0.000 * * *$ \\
\hline Effective human resource management & 24 & 1.00 & $0.000 * * *$ & 27 & 0.89 & $0.009 * * *$ \\
\hline Complaints management system & 23 & 1.00 & $0.000 * * *$ & 26 & 0.96 & $0.000 * * *$ \\
\hline Customer satisfaction assessment & 23 & 1.00 & $0.000 * * *$ & 26 & 0.92 & $0.003 * * *$ \\
\hline Customer requirements identification & 23 & 1.00 & $0.000 * * *$ & 24 & 0.88 & $0.022 * *$ \\
\hline Control of nonconforming product & 22 & 1.00 & $0.000 * * *$ & 27 & 0.85 & $0.030 * *$ \\
\hline Procedures documentation & 24 & 0.96 & $0.001 * * *$ & 26 & 0.81 & $0.096^{*}$ \\
\hline Internal audits & 24 & 0.96 & $0.001 * * *$ & 27 & 0.59 & 0.254 \\
\hline Evaluation of existing procedures & 24 & 0.96 & $0.001 * * *$ & 26 & 0.65 & 0.504 \\
\hline Implementation of corrective actions & 23 & 0.96 & $0.001 * * *$ & 27 & 0.81 & $0.077^{*}$ \\
\hline Fact based decision making & 23 & 1.00 & $0.000 * * *$ & 27 & 1.00 & $0.000 * * *$ \\
\hline Definition of quality management objectives & 24 & 1.00 & $0.000 * * *$ & 25 & 0.72 & 0.384 \\
\hline Definition of performance indicators & 24 & 1.00 & $0.000 * * *$ & 26 & 0.73 & 0.334 \\
\hline $\begin{array}{l}\text { Setting a strategy encompassing important aspects } \\
\text { of quality management }\end{array}$ & 23 & 0.96 & $0.001 * * *$ & 25 & 0.76 & 0.232 \\
\hline
\end{tabular}

\subsubsection{Change of the company culture}

This section tests the hypothesis that, before starting the ISO 9001 registration process, companies deliberately carry out initiatives to begin to change the organizational culture with the aim to create an internal organizational context that is more receptive to certification. The statistical test results are shown in Table 7. 
Table 7. Binomial tests results for hypothesis 3

\begin{tabular}{|c|c|c|c|c|c|c|c|c|}
\hline \multirow[b]{2}{*}{ H3 (culture) } & \multicolumn{4}{|c|}{2012} & \multicolumn{4}{|c|}{2014} \\
\hline & $\begin{array}{l}\text { No. of } \\
\text { hotels }\end{array}$ & $\begin{array}{c}\text { Proportion } \\
\text { observed }\end{array}$ & $\begin{array}{l}\text { Significanc } \\
\text { e level for } \\
\mathrm{H}_{0}: \pi \leq 0.33\end{array}$ & $\begin{array}{c}\text { Significance } \\
\text { level for } \mathrm{H}_{0} \text { : } \\
\pi \leq 0.67\end{array}$ & $\begin{array}{l}\text { No. of } \\
\text { hotels }\end{array}$ & $\begin{array}{c}\text { Proportion } \\
\text { observed }\end{array}$ & $\begin{array}{c}\text { Significance } \\
\text { level for } \mathrm{H}_{0} \text { : } \\
\pi \leq 0.33\end{array}$ & $\begin{array}{c}\text { Significance } \\
\text { level for } \mathrm{H}_{0} \text { : } \\
\pi \leq 0.50\end{array}$ \\
\hline $\begin{array}{l}\text { Initiatives are } \\
\text { taken to change } \\
\text { the company } \\
\text { culture }\end{array}$ & 17 & 0.85 & $0.000 * * *$ & $0.064 *$ & 11 & 0.52 & $0.052 *$ & 0.500 \\
\hline $\begin{array}{l}\text { Initiatives to } \\
\text { change the } \\
\text { company culture } \\
\text { are not taken }\end{array}$ & 3 & 0.15 & & & 10 & 0.48 & & \\
\hline Total & 20 & 1.00 & & & 21 & 1.00 & & \\
\hline
\end{tabular}

The significance levels obtained lead to rejection of $\mathrm{H}_{0}: \pi \leq 0.33$ in both years (2012 and 2014). Repeating the test for higher proportions $\pi$ of 50 and 67 percent, results in the rejection of $\mathrm{H}_{0}$ for the year 2012, but not for the year 2014.

Together, these results reveal a significand but undesirable evolution. While, in 2012, the majority of the hotel population (more than 67 percent) have considered it relevant to start changing culture before initiating a certification process, in 2014 only more than 33 percent of the hotels (but less than 50 percent) continued to consider that cultural change relevant.

\subsubsection{Incipient $Q M S$}

This section tests the hypothesis that, before starting the ISO 9001 registration process, companies deliberately take initiatives that lead to the installation of an incipient QMS. For a proportion, $\pi$, of ten percent, and assuming a significance level of $\alpha=0.10$, the decision is to reject $\mathrm{H}_{0}$ for both years of 2012 and 2014 (Table 8). 
Table 8 . Binomial tests results for hypothesis 4

\begin{tabular}{|c|c|c|c|c|c|c|c|c|}
\hline \multirow[b]{2}{*}{ H4 (incipient system) } & \multicolumn{4}{|c|}{2012} & \multicolumn{4}{|c|}{2014} \\
\hline & $\begin{array}{c}\text { No. } \\
\text { of } \\
\text { hotels }\end{array}$ & $\begin{array}{c}\text { Proportion } \\
\text { observed }\end{array}$ & $\begin{array}{l}\text { Significanc } \\
\text { e level for } \\
\mathrm{H}_{0}: \pi \leq 0.10\end{array}$ & $\begin{array}{l}\text { Significanc } \\
\text { e level for } \\
\mathrm{H}_{0}: \pi \leq 0.25\end{array}$ & $\begin{array}{c}\text { No. } \\
\text { of } \\
\text { hotels }\end{array}$ & $\begin{array}{c}\text { Proportion } \\
\text { observed }\end{array}$ & $\begin{array}{l}\text { Significanc } \\
\text { e level for } \\
\mathrm{H}_{0}: \pi \leq 0.50\end{array}$ & $\begin{array}{c}\text { Significanc } \\
\text { e level for } \\
H_{0}: \pi \leq 0.67\end{array}$ \\
\hline $\begin{array}{l}\text { There is a QMS } \\
\text { before starting the } \\
\text { certification process }\end{array}$ & 4 & 0.174 & $0.096^{*}$ & 0.432 & 21 & 0.724 & $0.012 * *$ & 0.344 \\
\hline $\begin{array}{l}\text { There is no QMS } \\
\text { before starting the } \\
\text { certification process }\end{array}$ & 19 & 0.826 & & & 8 & 0.276 & & \\
\hline Total & 23 & 1.000 & & & 29 & 1.000 & & \\
\hline
\end{tabular}

The tests, conducted again with higher $\pi$ values, including the 25, 50, and 67 percentages, provided different results for the two years considered. For the 2012 test, the p-value is 0.432 , leading to the non-rejection of hypothesis $\mathrm{H}_{0}: \pi \leq 0.25$. However, for the 2014 test, the result allows the rejection of hypothesis $H_{0}: \pi \leq 0.50$ (with $\alpha=0.05$ ), suggesting that, in that year, the proportion of hotels that in the population had an incipient QMS, before starting a certification process, was greater than 50 percent. These results further suggest that there has been some positive developments between the years on which the first survey was conducted (2012) and that on which the second survey was conducted (2014).

\section{Discussion}

This section summarizes the results (Table 9), discusses the research hypotheses, and presents the key findings from the analysis. 
Table 9. Summary of the hypotheses tests

\begin{tabular}{|c|c|c|c|}
\hline Hypotheses & 2012 & 2014 & Evolution over time, from 2012 to 2014 \\
\hline \multirow{2}{*}{ H1 (plan) } & $>33 \%$ & $>33 \%$ & \multirow{2}{*}{ Positive, but not significant development } \\
\hline & $\leq 50 \%$ & $\leq 50 \%$ & \\
\hline $\mathrm{H} 2$ (initiatives) & $>67 \%$ & $>67 \%$ & $\begin{array}{l}\text { In general, no significant evolution but, for some specific initiatives, the } \\
\text { proportion of companies in the population may have decreased from } 2012 \text { to } 2014 \text {. }\end{array}$ \\
\hline \multirow{2}{*}{ H3 (culture) } & $>33 \%$ & $>33 \%$ & \multirow{2}{*}{$\begin{array}{l}\text { Negative, the proportion of companies in the population may have decreased from } \\
\qquad 2012 \text { to } 2014\end{array}$} \\
\hline & $>67 \%$ & $\leq 50 \%$ & \\
\hline \multirow{2}{*}{$\begin{array}{l}\text { H4 (incipient } \\
\text { system) }\end{array}$} & $>10 \%$ & $>50 \%$ & \multirow{2}{*}{$\begin{array}{l}\text { Positive, the proportion of companies in the population may have increased from } \\
\qquad 2012 \text { to } 2014\end{array}$} \\
\hline & $\leq 25 \%$ & $\leq 67 \%$ & \\
\hline
\end{tabular}

The analysis of the results obtained in 2012 and 2014 shows that there has been a favourable evolution in the proportion of companies, in the population, that claim to have an incipient (noncertified) QMS (H4) before starting to implement ISO 9001. In fact, in 2012 this ratio was less than or equal to 25 percent, but by 2014 it was over 50 percent. Despite this good result, the proportion of companies that chose to develop a quality initiatives plan (H1) to be implemented before the start of the certification process has been low $(\leq 50 \%)$. There is, apparently, a lack of assessment of the situation, prior to the certification process, and a lack of thought and planning on what quality initiatives to put into practice before certification. However, most companies ( $>67$ percent) start such initiatives before certification (H2). This proportion remained high between 2012 and 2014, revealing the willingness to prepare the organization for certification, but without proper planning. Finally, the proportion of companies that begin to change the organizational culture, before starting the certification process $(\mathrm{H} 3)$, seems to show an undesirable evolution between 2012 and 2014, since this proportion falls from more than 67 percent to 50 percent or less.

These results provide empirical support to the ideas found in the literature review. Specifically, they provide support to the importance of initiating a cultural transformation that can make the organization more receptive to change (Terziovski et al, 1997, Yung, 1997; Detert et al, 2000, Haffar et al., 2017), the benefits of integrating quality into the 
organization through other quality initiatives or systems prior to certification (Withers et al., 1997; Terziovski and Power, 2007; Martínez-Costa et al., 2009), and the relevance of carrying out certain preparatory activities (Kotter, 2007) which include both soft and hard QMS elements, instead of only soft elements (Rahman and Bullock, 2005; Srinivasan and Kurey, 2014; Gambi et al., 2015).

However, the results obtained are surprising because of the limited importance given to the situation analysis and planning. Indeed, these results do not provide empirical support for the usefulness of an assessment of the company's situation before starting a certification process (contrary to Briscoe et al.'s, 2005, suggestion), or the need for a preparation plan to be carried out before the certification process (contrary to hypothesis H1).

Finally, the combined results of $\mathrm{H} 2$ and $\mathrm{H} 4$ for the year 2012 might be considered puzzling. Since most companies $(>67 \%)$ implement quality related actions/initiatives (H2), before implementing ISO 9001, the expected proportion of companies saying they have an incipient QMS (H4) should probably be higher than that that was found $(10 \%<\pi \leq$ $25 \%$ ). This unexpected result is addressed in the research limitations.

\section{Conclusion: contributions, implications and limitations}

Departing from several contributions identified in the literature review, this paper proposes a model that consolidates several ideas into one coherent whole (Figure 1). The model's originality lies, first, in the integration of the literature contributions and, second, in the proposition that organizations should elaborate an action plan composed of activities to be undertaken before the certification process and aimed at creating a more receptive environment for the successful implementation of ISO 9001. This article contributes also to the literature by presenting empirical data on the agreement of companies with each of the model's preparation activities. This article further contributes 
to the literature by raising several new research questions (and new research avenues): Do companies prepare for certification before starting certification? Do they prepare deliberately? Do they plan for those preparations? What preparations do they make? What specific actions are involved? How do they chose what to do first and what to do after starting certification? What is the effect of cultural types and cultural traits on the choice of what quality techniques to implement first? Can (and do) organizations start changing culture before starting certification? How can an incipient QMS be defined? Do organizations implement incipient QMS before certification? Should they implement? Is planning for the implementation of certain quality methods and initiatives compatible with the idea of an incipient QMS? Does an incipient QMS facilitate certification? Does an incipient QMS facilitate implementation of other QMS such as TQM, 'Q' (e.g., Alonso-Almeida et al., 2013), ISO 14000 and others?

This research entails some implications for management practice as well. Firstly, results suggest that prior existence of an incipient QMS can facilitate ISO 9001 certification. Secondly, adoption and gradual implementation of quality methods can contribute to creation of a more receptive internal environment for subsequent certification. Thirdly, ad hoc adoption of quality methods is not compatible with responsible management. More careful planning should probably be considered by management before adopting these initiatives. Unfortunately, according to this survey, most companies do not plan the adoption of quality initiatives. Fourthly, a large proportion of companies initiate culture change before starting certification in the belief that this change can also facilitate certification. Our results suggest that more companies should do this. Lastly, and one of the most significant implications from this research, a more coherent and integrated approach for ISO 9001 preparation is required from management. 
This paper starts to provide answers to some of the research questions outlined earlier and suggests some practical implications for management, but it also has some limitations. Firstly, the 2012 survey population is composed of four and five stars hotels in mainland Portugal whereas the 2014 survey population is composed of four and five stars hotels in mainland Portugal plus the autonomous regions of Madeira and the Azores. The inclusion of the autonomous regions in the second survey could have contributed to some of the differences between the results of 2012 and 2014, since the two valid responses to the questionnaire obtained from the Portuguese autonomous regions represent approximately seven percent of the sample.

Secondly, the study considers only companies in the hotel sector. Although the results may be valid for other services sectors, with characteristics similar to those of the hospitality sector, they cannot be generalized to other types of economic activities before studies such as this can be conducted in other industries.

Thirdly, the study considers only the ISO 9001 QMS. Although results may be valid for other QMS, they cannot be generalized before studies such as this can be conducted with Total QMSs, ISO 14000, and other QMSs.

Fourthly, the period under study is a period of economic crisis in Portugal. This economic downturn could have influenced the results. However, the tourism sector in Portugal did not suffer from the crisis in this period, and recorded a good performance in terms of several performance indicators (see, for instances, Eurostat, 2015a, 2015b). The fact that the tourism sector seems to have been shielded from the economic recession in Portugal might suggest that the study results could have also been shielded from the economic recession in this country.

Finally, the combined results of $\mathrm{H} 2$ and $\mathrm{H} 4$ for the year 2012 might be considered puzzling. Possible explanations for this puzzling result are (1) differences in the 
populations (limitation one), (2) random effects as a result of sampling, (3) respondents did not consider 'isolated' unplanned initiatives (H1, H2) as being a part of an incipient QMS (H4), (4) bad input data, (5) low understanding of the last question by respondents, and (6) other causes. Explanations (4) and (5) are, however, improbable given the care and effort put into designing and implementing the questionnaire (Section 3.2). Further research might also clarify this issue.

\section{Acknowledgement}

The authors are pleased to acknowledge financial support from Fundação para a Ciência e a Tecnologia (grant UID/ECO/04007/2013) and FEDER/COMPETE (POCI-01-0145FEDER-007659). The authors are pleased to acknowledge also the the contribution of the respondent companies in this study and the helpful comments from two anonymous reviewers.

\section{References}

Alonso-Almeida, M.M., Marimon, F. and Bernando, M. (2013). Diffusion of quality standars in the hospitality sector. International Journal of Operations \& Production Management, 33(5), 504-527.

Anttila, J. and Jussila, K. (2017). ISO 9001:2015 - A questionable reform. Total Quality Management \& Business Excellence, 28(9-10), 1090-1105.

Balogun, J. and Hailey, V.H. (2015). Exploring Strategic Change. Essex: Pearson.

Bisgaard, S. (2008). Quality management and Juran's legacy. Quality Engineering, 20(4), 390-401.

Briscoe, J.A, Fawcett, S.E. and Todd, R.H. (2005). The implementation and impact of ISO 9000 among small manufacturing enterprises. Journal of Small Business Management, 43(3), 309-330.

Cândido, C.J.F. (2005). Service quality strategy implementation - A model and the case of the Algarve hotel industry. Total Quality Management \& Business Excellence, $16(1), 3-14$. 
Cândido, C.J.F. (2010). Service Quality Strategy: Implementation in Algarve Hotels, In Silva, João A., Jafari, Jafar and Noel Scott (Eds.) Tourism Development and Management: Challenges and Opportunities for Algarve, Portugal (pp. 163-181). Faro: Universidade do Algarve.

Cândido, C.J.F., Coelho, L.M.S. and Peixinho, R.M.T. (2016). The financial impact of a withdrawn ISO 9001 Certificate, International Journal of Operations \& Production Management, 36(1), 23-41.

Cândido, C.J.F. and Santos, S.P. (2011). Is TQM more difficult to implement than other transformational strategies? Total Quality Management \& Business Excellence, 22(11), 1139-1164.

Cândido, C.J.F. and Santos, S.P. (2015). Strategy implementation: What is the failure rate? Journal of Management and Organization, 21(2), 237-262.

Chaiprasit, K., Jariangprasert, N., Chomphunut, A., Naparat, D. and Jaturapatarapom, J. (2011). Tourist expectations toward travel and tourism websites in Thailand. International Business \& Economics Research Journal, 10(3), 41-50.

Croft, N., Fonseca, L. and Domingues, P. (2016). ISO 9001 survey: auditors give their verdict. Quality World, September, 38-40.

Dalmau, J.C., Gimenenz, G. and Castro, R. (2016). ISO 9001 aspects related to performance and their level of implementation. Journal of Industrial Engineering and Management, 9(5), 1090-1106.

Detert, L.R., Schroeder, R.G. and Mauriel, J.J. (2000). A framework for linking culture and improvement initiatives in organizations. Academy of Management Review, 25(4), 850-863.

Evans, J.R. and Lindsay, W.M. (2014). Managing for Quality and Performance Excellence. USA: Cengage.

Eurostat (2012). Europe in Figures, Eurostat Yerbook 2012. Luxembourg: Publications Office of the European Uninon.

Eurostat (2015a). Nights spent at tourist accommodation establishments by residents/nonresidents. Downloaded from: http://ec.europa.eu/eurostat, October.

Eurostat (2015b). Net occupancy rate of bed-places and bedrooms in hotels and similar accommodation. Downloaded from: http://ec.europa.eu/eurostat, October.

Feng, M., Terziovski, M. and Samson, D. (2008). Relationship of ISO 9001:2000 quality system certification with operational and business performance. Journal of Manufacturing Technology Management, 19(1), 22-37. 
Gambi, L.N., Boer, H., Gerolamo, M.C., Jørgensen, F. and Carpinetti, L.C.R. (2015). The relationships between organizational culture and quality techniques and its impact on operational performance. International Journal of Operations \& Production Management, 35(10), 1460-1484.

Gotzamani, K.D. and Tsiotras, G.D. (2001). An empirical study of the ISO 9000 standards' contribution towards total quality management. International Journal of Operations \& Production Management, 21(10), 1326-1342.

Haffar, M., Al-Karaghouli, W., Djebarni, R. and Gbadamosi, G. (2017). Organisational culture and TQM implementation. Total Quality Management \& Business Excellence, 2017, 1-22.

Hughes, T., Williams, T., Ryall, P. (2000). It is not what you achieve it is the way you achieve it. Total Quality Management, 11(3), 329-340.

INE (2013). Estatísticas do Turismo 2012. Lisboa: INE.

INE (2015). Estatísticas do Turismo 2014. Lisboa: INE.

ISO (2008). ISO 9001:2008 Quality Management Systems Requirements. Geneva: ISO.

ISO (2015). ISO 9001:2015 Quality Management Systems Requirements. Geneva: ISO.

ISO (2016). The ISO survey 2015. Geneva: ISO.

Juran, J.M. and Gryna, F.M. (1993). Quality Planning and Analysis. New York: McGrawHill.

Kanji, G.K. and Sá, P.M. (2002). Kanji’s business scorecard. Total Quality Management, 13(1), 3-27.

Karapetrovic, S., Casadesús, M. and Saizarbitoria, I.H. (2010). What happened to the ISO 9000 lustre? An eight-year study. Total Quality Management \& Business Excellence, 21(3), 245-267.

Kaziliūnas, A. (2010). Impacts of different factors on the implementation of quality management systems and performance outcomes. Current Issues of Business \& Law, $5(1), 75-92$.

Kotter, J.P. (2007). Leading change: why transformation efforts fail. Harvard Business Review, 85(1), 96-103.

Lo, L.K. and Chang, D.S. (2007). The difference in the perceived benefits between firms that maintain ISO certification and those that do not. International Journal of Production Research, 45(8), 1881-1897.

Mahony, K. (2007). Certification in the South African tourism industry: the case of Fair Trade in Tourism. Development Southern Africa, 24(3), 393-408. 
Martínez-Costa, M., Choi, T.Y., Martínez, J.A. and Martínez-Lorente, A.R. (2009). ISO 9000/1994, ISO 9001/2000 and TQM: The performance debate revisisted. Journal of Operations Management, 27(6), 495-511.

Martínez-Lorente, A. and Martínez-Costa, M. (2004). ISO 9000 and TQM: substitutes or complementaries? International Journal of Quality \& Reliability Management, 21(3), 260-276.

Naor, M., Goldstein, S.M., Linderman, K.W. and Schroeder, R.G. (2008). The role of culture as driver of quality management and performance. Decision Sciences, 39(4), 671-702.

Rahman, S. (2001). A comparative study of TQM practice and organisational performance of SMEs with and without ISO 9000 certification. International Journal of quality \& Reliability Management, 18(1), 35-49.

Rahman, S. (2004). The future of TQM is past. Can TQM be resurrected? Total Quality Management \& Business Excellence, 15(4), 411-422.

Rahman, S. and Bullock, P. (2005). Soft TQM, hard TQM, and organisational performance relationships: an empirical investigation. Omega, 33(1), 73-83.

Rybski, C., Jochem, R. and Homma, L. (2017). Empirical study on status of preparation for ISO 9001:2015. Total Quality Management \& Business Excellence, 28(9), 10761089.

Schein, E.H. (1983). The role of the founder in creating organizational culture. Organizational Dynamics, 12(1), 13-2.

Singels, J., Ruël, G. and Van de Water, H. (2001). ISO 9000 series certification and performance. International Journal of Quality \& Reliability Management, 18(1), 6275.

Srinivasan, A. and Kurey, B. (2014). Creating a culture of quality. Harvard Business Review, 92(4), 23-25.

Stăncioiu, A., Teodorescu, N., Pârgaru, I., Vlădoi, A. and Băltescu, C. (2011). The image of the tourism destination. Theoretical \& Applied Economics, 18(2), 139-152.

Terziovski, M. and Power, D. (2007). Increasing ISO 9000 certification benefits: a continuous improvement approach. International Journal of Quality \& Reliability Management, 24(2), 141-163.

Terziovski, M., Samson, D. and Dow, D. (1997). The business value of quality management systems certification. Journal of Operations Management, 15(1), 1-18. 
Valmohammadi, C. and Roshanzamir, S. (2015). The guidelines of improvement: Relations among organizational culture, TQM and performance. International Journal of Production Economics, 164, 167-178.

Vloeberghs, D. and Bellens, J. (1996). Implementing the ISO 9000 standards in Belgium. Quality Progress, 29(6), 43-48.

Withers, B.E., Ebrahimpour, M. and Hikmet, N. (1997). An exploration of the impact of TQM and JIT on ISO 9000 registered companies. International Journal of Production Economics, 53(2), 209-216.

Yung, W.K.C. (1997). The values of TQM in the revised ISO 9000 quality system. International Journal of Operations \& Productions Management, 17(2), 221-230. 